\title{
Personality and Disease
}

\author{
John P. Capitanio, Ph.D. \\ California National Primate Research Center, Department of Psychology, University of California, \\ Davis
}

Once again, the patient as a human being with worries, fears, hopes, and despairs, as an indivisible whole and not merely the bearer of organs - of a diseased liver or stomach - is becoming the legitimate object of medical interest

(Alexander, 1950, p. 17).

This opening quote from Franz Alexander's classic 1950 work "Psychosomatic Medicine" launches a discussion of what Alexander viewed as progress during the preceding two decades in understanding the role of emotional factors in disease. The quote also frames this special issue of Brain, Behavior, and Immunity: What generates the "worries, fears, hopes, and despairs" and what are the immunologic mechanisms by which they affect disease-related processes? We know now that there are many contributors, within the organism, to these psychological states, from many different levels of analysis - genotype, levels of neurotransmitters, one's previous experiences, one's degree of emotional reactivity, and so forth. Of course, all of these levels are interrelated, and the role that "worries, fears, hopes, and despairs" play in health and disease can be investigated profitably at each. In this special issue, we focus on a hypothetical construct, personality, that represents the confluence of those contributors that the organism brings to the situations it encounters and chooses. There are three reviews and a dozen empirical papers that focus on the topic of personality and disease. In this Commentary, I provide some background and historical context for this special issue, and focus especially on how the reviews in this issue provide complementary perspectives on the topic.

\section{Why "personality"?}

At a fundamental level, personality refers to how and why an individual responds to her environment. Alexander (1950, p. 34) defined it as "the expression of the unity of the organism," and the personality psychologist Gordon Allport considered it "the dynamic organization within the individual of those psychophysical systems that determine his unique adjustments to his environment" (Allport 1937, p. 48). Thus, personality is inside the individual, but it mediates her responses ("adjustments") to the environment. This is an important distinction - personality is related to behavior (i.e., responses, adjustments), but is not the same as behavior. Rather, it reflects a higher-order construct that we typically infer from behavior, and especially from patterns of behavior exhibited over time.

Importantly, nothing that I've said so far about personality is specific to humans. Pet owners frequently describe their animals using personality-related terms because animals, too, have

Corresponding author: John P. Capitanio, Ph.D., California National Primate Research Center, One Shields Ave., University of California, Davis, CA 95616, tel: 530-752-4002, fax: 530-752-2880, email: jpcapitanio@ucdavis.edu.

Publisher's Disclaimer: This is a PDF file of an unedited manuscript that has been accepted for publication. As a service to our customers we are providing this early version of the manuscript. The manuscript will undergo copyediting, typesetting, and review of the resulting proof before it is published in its final citable form. Please note that during the production process errors may be discovered which could affect the content, and all legal disclaimers that apply to the journal pertain. 
habitual patterns of response that they tend to use in similar situations. The scientific study of animal personality has grown rapidly in the past decade, and the review by Mehta and Gosling (2008) explicitly focuses on the issue of animal personality, and the benefits of a comparative approach to studying personality-health relationships. As Mehta and Gosling (2008) note, the term for the phenomenon under study sometimes varies according to scientific discipline (personality, temperament, behavioral syndromes), but the concepts are identical: patterns of behavior that are consistent over time. In fact, four of the 12 empirical papers in this issue are animal studies (Azpiroz et al., 2008; Capitanio et al., 2008; Cavigelli et al., 2008; and Sloan et al., 2008).

What are the dimensions of personality? Historically, personality has been conceptualized in two ways: as traits (which reflect dispositions to respond), and as motives (which reflect concern with, and striving toward, a certain class of incentives or goals [Emmons, 1989]). Trait approaches to personality have generally emphasized a small number of broad factors. The most popular trait approach in the current human literature is the Five Factor Model, comprising Agreeableness, Conscientiousness, Extraversion, Neuroticism, and Openness to Experience. Motive approaches have included the "Big Three" of Achievement, Affiliation, and Power.

Few psychologists would agree, however, that these eight terms describe all there is to know about personality or about adjustments to the environment. In fact, psychologists often invoke the concept of "coping" to describe explicitly how individuals adjust to stressful environments. How one copes is closely related to personality - individuals high in neuroticism often employ less effective coping strategies, responding with self-blame and hostility, while extraverts often display more effective coping strategies, such as seeking social support. Characteristics of the specific context also affect how personality influences coping -extraversion may not be influential in how one copes with being stranded alone on a desert island, but one's level of neuroticism might. And, of course, coping can reflect the interaction of personality and situational influences; for example, individuals with a different mix of personality characteristics may appraise, or cope with, a given situation very differently (Lee-Baggley et al., 2005).

The papers in this issue report research on a variety of personality traits, many of which are more specific than the broad ones just described; styles of coping with stress that have traitlike characteristics; and personality by situation interactions. The processes studied include active coping style (Azpiroz et al., 2008); trait anxiety (Buske-Kirschbaum et al., 2008); sociability (Capitanio et al., 2008; Sloan et al., 2008); active temperament (Cavigelli et al., 2008); Type D personality (a constellation of traits including negative affect and social inhibition; Denollet et al., 2008); the ability to regulate the expression of anger (Gouin et al., 2008); hostility and negative affect (Marsland et al., 2008); trait depression (Rohleder \& Miller, 2008); trait repetitive thought (which is related to neuroticism and openness to experience; Segerstrom et al., 2008); self-regulation of emotion in relation to goals (which is related to negative affect; Strauman et al., 2008); and Type C coping (involving a lack of emotional expression and communication of emotions and needs; Temoshok et al., 2008).

\section{Personality and disease in historical context}

How does personality relate to disease? Interest in such a relationship dates back to Greek and Roman times and the "humoral theory" commonly associated with Hippocrates of Cos. Four fluids (or "humors") - blood, black bile, phlegm, and yellow bile - filled the body; health resulted from a proper balance among the humors, and illness resulted from an imbalance. Five hundred years after Hippocrates made the humoral theory the basis for medicine, Galen broadened the theory to incorporate the concept of temperament. Although the meaning of "temperament" has evolved since Galen's time (Siegel, 1973), the links were certainly there: 
black bile, for example, which was associated with the spleen, formed the basis for a melancholic temperament, manifested as fear, depression, and discontent with life. Galen identified three types of melancholia, one of which was melancholia hypochondriaca, where abdominal organs were involved, giving rise to flatulence and digestive disturbances (Jackson, 1978).

It was, however, the development of the field of psychosomatic medicine that elaborated the idea that personality was influential in the development of physical disease. Flanders Dunbar (1943) described personality profiles that were associated with particular diseases. For example, patients suffering from coronary insufficiency and occlusion were described as "topdogs" or "would-be-top-dogs." More specifically, such patients tended to work long hours and not take vacations; tended to seize authority; and used conversation as "an instrument of domination and aggression" (p. 586). These individuals had few early neurotic traits, except perhaps a tendency to brood, but later in life could develop a tendency toward depression as well as a "compulsive asceticism and drive to work" (p. 590). They tended to take stimulants to enable them to continue working, showed little interest in sports and had few hobbies, and were generally skeptical about religion. Dunbar recognized, of course, that many individuals with no disease share many of these characteristics. It was, rather, in their co-occurrence, that the characteristics possess diagnostic value.

Alexander (1950), however, discussed a need to understand the mechanisms by which personality could affect a disease process, and his focus was on emotional states and adjustments to the environment, rather than superficial personality types, per se. In talking specifically about Dunbar's personality profile of the coronary patient, he states:

It might well be that a certain type of living, certain types of mental exertion, create somatic conditions conducive to certain progressive changes in the vascular system resulting ultimately in coronary disease. The true correlation may be not between personality make-up and coronary disease but between the mode of living and disease (p. 73).

and further:

For example, chronically sustained hostile impulses can be correlated with a chronic elevation of the blood pressure while dependent help seeking trends go with increased gastric secretions. These emotional states, however, may occur in a great number of very different personalities... A mysterious and vague correlation between personality and disease does not exist; there is a distinct correlation between certain emotional constellations and certain vegetative innervations. Whatever correlation is found between personality type and somatic disease is only of relative statistical validity and often incidental... The true psychosomatic correlations are between emotional constellations and vegetative responses ( $\mathrm{pp} 74-75$ ).

Thus, for Alexander, the influence of personality on disease lay more in its relationship with emotional responsiveness to the conditions of one's life, rather than with superficial typologies. The same pattern of emotional responsiveness (what we might call "coping") can be found in individuals with different personality types.

This more sophisticated view of the influence of personality - that is, a focus on what personality DOES for individuals in the situations it encounters - was evident in a more modern treatment of personality and disease (Friedman, 1990a). Many of the contributions in that volume emphasized the dynamic processes involved in psychological coping - exemplified by individuals' changing their cognitive and emotional efforts during the course of dealing with a stressful circumstance. Thus, the emphasis was more explicitly on emotional responses as a reflection of an interaction between an individual (and his personality) and the situation: "The 
person-environment 'match' or 'mismatch' is sometimes more important than either the person or the environment (Friedman, 1990b, p. 284)." And it's important to recognize that the "environment" must be carefully considered: "Individuals should be examined in their naturally occurring social contexts. Studies that bring Type A and Type B people into a lab and put their arms into an ice bucket have lots of experimental control but very little in the way of implications for the broader questions of personality and disease (p. 290)". Koolhaas reiterates this point in his review in the present issue (2008), which places individual variation in coping style among animals within the broader context of evolution and ecology: "Rather than pushing the animal towards a stress physiological ceiling, stressors should somehow challenge the natural defense mechanisms and hence call upon the adaptive capacity of the animal. The specific ecology and evolutionary biology of the species should be the basis to determine if one can expect the individual to have an adequate answer to a given challenge."

\section{Complexity in personality/disease relationships}

The empirical papers in this special issue focus on a variety of immune mechanisms that can mediate the relationship between personality and a disease process (or, in some cases, the prevention of a disease process, as in vaccination and rapid wound healing). It is important to note, however, that the personality/disease relationship may not always directly involve immunologic processes. This point is made clearly in the third review in this issue by Friedman (2008), who discusses multiple models of this relationship. Whole organisms make choices, and these choices involve, among others, which kinds of situations (healthy or unhealthy) they expose themselves to, their performance of particular health behaviors, and their adherence to recommended treatments. Personality can affect all of these processes. Thus, while the empirical papers in this issue report important advances in our understanding of how personality affects disease-related processes via immunologic mechanisms, it's important to keep in mind that personality and disease are part of a larger biosocial and temporal context that involves non-immune-related mediators of personality/disease relationships as well as conditions upon which personality/disease relationships may be contingent (e.g., genetic disease risk, exposure to stressful situations that activate appraisal and coping, cultural norms surrounding illness).

Both "personality" and "disease" are complex constructs, and so, not surprisingly, is their interaction. On the one hand, diseases are quite variable, with different ones showing different characteristics - time courses (e.g. HIV disease vs. influenza), type of immune involvement (e.g., depending on the mechanisms of action of different pathogens), and so on. Personality itself is a complex construct, involving multiple dimensions, each of which may be more important in some situations than in others, and each of which affects the expression of others (for example, consider how someone high in extraversion might behave in general, depending on whether they are high or low on neuroticism). And the situations of one's life are equally complex - some are chosen (wisely or unwisely), while some are imposed upon us. While personality may exert main effects on disease processes (e.g., some traits may be associated with variation in lymph node innervation patterns, or with tendencies toward a general proinflammatory phenotype, or with regulation of the hypothalamic-pituitary-adrenal axis, each of which could influence a variety of diseases), much of the role played by personality in disease will be more interactionist, a reflection of personality's role in affecting how individuals appraise and cope with situations, and the emotional responses they generate. Papers reflecting both of these approaches are present in this special issue.

One final note. When I give talks on the role of personality factors and disease, I often have someone ask me whether they are "doomed" because they are not conscientious or sociable. Personality is not destiny in this regard. A better understanding of the mechanisms by which personality affects disease processes will hopefully be accompanied by new options for 
treatment, either pharmacologic (e.g., drugs, like beta blockers, that might dampen sympathetic nervous system action in lymphoid tissue) or psychological (e.g., through helping individuals develop better coping strategies). This aspect of the personality/disease relationship is not addressed in this special issue, but will be an important direction in the future, as we attempt to translate our findings into clinical outcomes.

The authors in the present volume have generously contributed new data that improve our understanding of one component of the complex relationship between personality and disease, namely immune mechanisms that mediate this relationship. I thank them for their contributions, and their helpfulness during the development of this special issue. In addition, a special thanks goes to Keith Kelley, Editor-in-Chief of BBI, for the opportunity to assemble this collection of papers, and for advice and encouragement throughout the process. Finally, I greatly appreciate the logistic support provided by Shannon Tomlinson, in the BBI editorial office.

\section{References}

Alexander, F. Psychosomatic Medicine: Its Principles and Applications. Norton; New York: 1950.

Allport, GW. Personality: A Psychological Interpretation. Holt; New York: 1937.

Azpiroz A, De Miguel Z, Fano E, Vegas O. Relations between different coping strategies for social stress, tumor development and neuroendocrine and immune activity in male mice. Brain, Behavior, and Immunity. 2008this issue

Buske-Kirschbaum A, Ebrecht M, Kern S, Gierens A, Hellhammer DH. Personality characteristics in chronic and non-chronic allergic conditions. Brain, Behavior, and Immunity. 2008this issue

Cavigelli SA, Bennett JM, Michael KC, Klein LC. Female temperament, tumor development and life span: Relation to glucocorticoid and tumor necrosis factor- $\alpha$ levels in rats. Brain, Behavior, and Immunity. 2008this issue

Capitanio JP, Abel K, Mendoza SP, Blozis SA, McChesney MB, Cole SW, Mason WA. Personality and serotonin transporter genotype interact with social context to affect immunity and viral set-point in simian immunodeficiency virus disease. Brain, Behavior, and Immunity. 2008this issue

Denollet, J.; Vrints, CJ.; Conraads, VM. Brain, Behavior, and Immunity. 2008. Comparing Type D personality and older age as correlates of tumor necrosis factor- $\alpha$ dysregulation in chronic heart failure. this issue

Dunbar, F. Psychosomatic Diagnosis. Hoeber; New York: 1943.

Emmons, RA. Exploring the relations between motives and traits: The case of narcissism. In: Buss, DM.; Cantor, N., editors. Personality Psychology: Recent Trends and Emerging Directions. SpringerVerlag; New York: 1989. p. 32-44.

Friedman, HS. Personality and Disease. Wiley; New York: 1990a.

Friedman, HS. Where is the disease-prone personality? Conclusion and future directions. In: Friedman, HS., editor. Personality and Disease. Wiley; New York: 1990b. p. 283-292.

Friedman HS. The multiple linkages of personality and disease. Brain, Behavior, and Immunity. 2008this issue

Gouin J-P, Kiecolt-Glaser JK, Malarkey WB, Glaser R. The influence of anter expression on wound healing. Brain, Behavior, and Immunity. 2008this issue

Jackson SW. Melancholia and the waning of humoral theory. J Hist Medicine 1978;33:367-376.

Koolhaas JM. Coping style and immunity in animals: making sense of individual variation. Brain, Behavior, and Immunity. 2008this issue

Lee-Baggley D, Preece M, DeLongis A. Coping with interpersonal stress: Role of Big Five traits. J Personality 2005;73:1141-1180. [PubMed: 16138869]

Marsland AL, Prather AA, Petersen KL, Cohen S, Manuck SB. Antagonistic characteristics are positively associated with inflammatory markers independently of trait negative emotionality. Brain, Behavior, and Immunity. 2008this issue

Mehta PH, Gosling SD. Bridging human and animal research: A comparative approach to studies of personality and health. Brain, Behavior, and Immunity. 2008this issue 
Rohleder N, Miller GE. Acute deviations from long-term trait depressive symptoms predict systemic inflammatory activity. Brain, Behavior, and Immunity. 2008this issue

Segerstrom SC, Schipper LJ, Greenberg RN. Caregiving, repetitive thought, and immune response to vaccination in older adults. Brain, Behavior, and Immunity. 2008this issue

Siegel, RE. Galen on Psychology, Psychopathology, and Function and Diseases of the Nervous System. Basel; Karger: 1973.

Sloan EK, Capitanio JP, Tarara RP, Cole SW. Social temperament and lymph node innervation. Brain, Behavior, and Immunity. 2008this issue

Strauman TJ, Coe CL, McCrudden MC, Vieth AZ, Kwapil L. Individual differences in self-regulatory failure and menstrual dysfunction predict upper respiratory infection symptoms and antibody responses to flu immunization. Brain, Behavior, and Immunity. 2008this issue

Temoshok LR, Waldstein SR, Wald RL, Garzino-Demo A, Synowski SJ, Sun L, Wiley JA. Type C coping, alexithymia, and heart rate reactivity are associated independently and differentially with specific immune mechanisms linked to HIV progression. Brain, Behavior, and Immunity. 2008this issue 